\title{
Mercaderes castellanos a fines de la Edad Media: peligros y salvaguardas en la Carrera a Flandes
}

\author{
Castilian Merchants at the end of the Middle Ages: Dangers and Safeguards \\ in Wool Race or Route to Flanders
}

\author{
Dra. Gloria Cristina FLÓREZ \\ Universidad Nacional Mayor de \\ de San Marcos (Lima, Perú) \\ florezdgc@gmail.com
}

\begin{abstract}
Resumen: El Reino de Castilla a fines de la Edad Media tuvo una importante actividad económica, destacando el comercio con Europa septentrional en la llamada Carrera a Flandes donde la lana era el producto preponderante. La ruta iniciada en el siglo XIII alcanzó su apogeo en el siglo XV siendo actores importantes los productores de la lana y los mercaderes, así como transportistas y personal marinero, castellanos y vascos, quienes necesitaron defenderse mediante diferentes medios de las graves amenazas, naturales o humanas que se presentaban, destacando entre ellas la piratería.
\end{abstract}

Abstract: By the end of the Middle Ages, the Kingdom of Castile had an important economic activity, standing out the commerce with Northern Europe in the so called Route to Flanders where wool was a main product. This route began in the XIII century reaching its peak in the XV century, being important wool producers and merchants, as well as, maritime carriers, Castilians and Basques crew who faced serious threats as humans, natural disasters and piracy.

Palabras clave : Mercaderes castellanos- Carrera a Flandes o de la LanaFlandes- Castilla- Consulado de España- piratería- siglos XIV-XV

Keywords: Castilian Merchants - Route to Flanders or Wool Race - Flanders Castile - Spanish Consulate - Piracy- XIV-XV Centuries. 
Sumario:

I. Introducción.

II. Castilla y Flandes a fines de la Edad Media.

III. Aspectos del comercio marítimo español: La Carrera a Flandes o Carrera de la Lana.

IV. Peligros y salvaguardas de los mercaderes castellanos en la Carrera a Flandes.

Recibido: diciembre 2019.

Aceptado: enero 2020. 


\section{INTRODUCCIÓN}

Nuestro trabajo ha considerado tres elementos fundamentales para el análisis: el marco cronológico, importante para las sociedades castellanas y flamencas que presentaban profundas transformaciones, y al mismo tiempo importantes permanencias, tal como sucedía en otras regiones europeas. En cuanto al ámbito geográfico, mostraba la existencia de la "unidad económica", extendiéndose desde la región ibérica hasta las regiones septentrionales, siendo el eje la región de Flandes. Finalmente, los grupos humanos que constituían los actores participantes en la Carrera de la Lana: mercaderes, navegantes, armadores, autoridades, así como los personajes que representaban el peligro por sus actividades ilícitas: piratas y corsarios. La documentación utilizada proviene de la Sección Gobierno del Registro General del Sello (1474-1494) en el Archivo General de Simancas en Valladolid (España), complementada con diferentes fuentes editadas como los Cartularios y Ordenanzas ${ }^{1}$, así como Crónicas de la época. Hemos presentado y publicado avances de un trabajo todavía inédito, Mercaderes y política en la época de Isabel la Católica.

Hemos tenido en cuenta para la realización de nuestro trabajo, las propuestas del profesor Jean Delumeau ${ }^{2}$, quien tuvo la amabilidad de explicar sus propuestas sobre el miedo y la inseguridad, incluso posteriormente me brindó la posibilidad de traducir su Lección final en el Collège de France ${ }^{3}$. Asimismo, era importante ampliar esta información con sus publicaciones previas, algunas traducidas a nuestro idioma pero sin embargo, en ciertos casos no ha existido esa posibilidad. Por tal razón, quiero incluir sus importantes aportes que nos permiten comprender mejor a los grupos estudiados.

Delumeau en su artículo Pouvoir, peur et hérésie au début des Temps Modernes ${ }^{4}$ considera que la omnipresencia del miedo en las sociedades se da

\footnotetext{
${ }^{1}$ GILLIODTS VAN SEVEREN, L., Cartulaire de l'ancien consulat d'Espagne à Bruges y Inventaire des archives de la ville de Bruges, así como las Ordenanzas del Consulado de Burgos.

${ }^{2}$ DELUMEAU, J., La peur en occident. XIV-XVIIIe siècles, Paris 1978, pp. 38-39.

${ }^{3}$ DELUMEAU, J., "Mentalidades religiosas en el Occidente moderno. Balance de una investigación" en Lienzo (Lima), 18 (1997) 265-283.

${ }^{4}$ La Peur. Recherches et débats, Paris 1979, p.12.
} 
en varios niveles, en el más profundo las aprehensiones viscerales solidarias de toda civilización mal provista técnicamente. En un nivel intermedio, se encuentran los miedos coyunturales, ligados a amenazas recurrentes: pestes, hambrunas, alza de impuestos, tránsito de soldados y vagabundos. Esos miedos han acompañado a las sociedades desde fines de la Edad Media hasta los inicios de la civilización industrial. Finalmente, en el nivel superior, de conciencia más lúcida, aparecen los miedos resultantes de los precedentes pero dándoles un nuevo significado. Sin embargo, nos interesa también explicar brevemente como su análisis del sentimiento de seguridad es importante en las sociedades estudiadas. Partiendo del análisis lingüístico ha explicado la relación del vocabulario con hechos objetivos pero también con un estado del espíritu y de qué manera los aspectos de confianza material se relacionan con la seguridad espiritual ${ }^{5}$.

En cuanto a la piratería, actividad que es definida como el asalto y saqueo a las naves y sus ocupantes, generalmente utilizando la violencia, asociada por lo regular con personajes como Henri Morgan, islas en las Antillas como Tortuga y la ciudad de Port Royal pero sobre todo con imágenes ofrecidas en las novelas de Salgari o en las películas Piratas del Caribe. En realidad, sus orígenes son anteriores a la era cristiana y han tenido períodos y regiones de mayor incidencia y sus acciones no se limitaban al ataque o la destrucción de naves. Podían también realizar desembarcos y pillajes en puertos, incluso invadiendo islas y estableciéndose en ellas. Controlada por los romanos, la piratería resurgió a partir de la crisis del siglo III de nuestra era, aumentando la inseguridad en las zonas meridionales y septentrionales de Europa.

A partir del siglo VIII, nuevos grupos de piratas se hicieron presentes en diferentes regiones europeas, sarracenos y vikingos aterrorizando a las poblaciones costeras, así como a los viajeros a quienes podían despojar de sus bienes, la libertad o la vida. Pese a los esfuerzos realizados por la Cristiandad, tanto en Occidente como en Oriente, el peligro de los diferentes grupos islámicos no desapareció en el Mediterráneo y sus costas, incluso ampliaron su radio de acción luego de la toma de Constantinopla en 1453. Sin embargo, sus acciones son menos conocidas en las zonas costeras de los mares Cantábrico, Báltico y del Norte, donde se realizaban importantes intercambios comerciales que favorecieron el desarrollo de Castilla, Flandes e Inglaterra. La inseguridad que se incrementó en las rutas marítimas en los últimos siglos de la Edad Media se expresa en numerosos documentos de la época y dio lugar a una serie de modificaciones en el comercio como las medidas de protección para los

5 DELUMEAU, J., Rassurer et protéger Le sentiment de sécurité dans l'Occident d'autrefois, Paris 1989, pp. 9-20. 
mercaderes y sus bienes, la creación de asociaciones de defensa, la mayor difusión de ciertos medios de pago y de seguros marítimos y el fomento del derecho mercantil.

\section{CASTILLA Y FLANDES A FINES DE LA EDAD MEDIA}

En la Baja Edad Media se conocía a la Península Ibérica como "España de los cinco Reinos": los Países de la Corona de Aragón, Portugal, Navarra, Castilla, todos ellos cristianos y el reino musulmán de Granada. Los territorios castellanos destacaban por su ubicación entre el Atlántico y el Mediterráneo, así como por su extensión $\left(355,000 \mathrm{~km}^{2}\right)$. No obstante, esas ventajas se veían limitadas por la diferenciación geográfica y la falta de unidad, agravada por la integración de provincias muy diferentes y, posteriormente, la incorporación de Castilla la Nueva y Andalucía.

En lo demográfico, es difícil conocer con exactitud el número de habitantes porque la información es contradictoria y, en ciertos casos, errónea. Los especialistas la calculan entre 4 a 5 millones de habitantes y si consideramos la importancia de la agricultura y ganadería, es comprensible el peso de una población rural mayoritaria. No obstante, se observa un creciente proceso de urbanismo en las regiones cántabra y andaluza. Esa sociedad se caracterizó por profundas distinciones entre poderosas minorías y mayorías disminuidas o desposeídas, marcadas diferencias al interior de los grupos sociales, tensiones y conservadurismo a pesar de la existencia de una cierta movilidad social.

En el aspecto político poseía rasgos sumamente interesantes donde se observan elementos característicos del mundo medieval y una serie de condicionamientos propios del periodo denominado "génesis del Estado Moderno" y que dieron forma a la monarquía española de los siglos siguientes. Debemos considerar el papel desempeñado por la institución monárquica en Castilla durante la Edad Media, así como su significado tanto en lo teórico como en lo práctico. El rey castellano, Gratia dei Rex, concentra en su persona los diversos atributos regios (Regalia), incorporándose posteriormente amplios poderes religiosos. Sin embargo, existían limitaciones importantes en lo práctico como casos relacionados con la minoría de edad o la debilidad de los monarcas, las regencias o la actitud de la nobleza. En cuanto a lo teórico, se refieren a la teoría eclesiástica del carácter contractual del poder y el derecho tradicional juramentado ante las Cortes. En la política exterior notamos las modificaciones presentadas desde el ascenso de la dinastía Trastámara; mayor acercamiento a la monarquía francesa, a diferencia de las amistosas relaciones existentes anteriormente con Inglaterra, así como el establecimiento de representaciones diplomáticas permanentes, enfrentamientos bélicos importantes y el interés por alianzas matrimoniales favorables. 
Las bases de la economía castellana eran la agricultura y la ganadería, así como el comercio exterior complementándose con la artesanía e industria y el comercio interno. La crisis de la Edad Media Tardía afectó el proceso roturador y solamente en el siglo XV se pasó a un período de "reconstrucción", como lo explica Valdeón Baruque ${ }^{6}$ pero definiéndose, al mismo tiempo, las formas características de explotación de la tierra. En cuanto a la ganadería, especialmente lanar, se relacionó estrechamente con el comercio de exportación y eso explica el interés de los propietarios, armadores y mercaderes de paños en beneficiarla. Por tal razón, tenía papel preponderante desde el siglo XIII y fueron de gran ayuda ciertos logros como la obtención de lana merina, la creación del Honrado Consejo de la Mesta, el fortalecimiento del poder nobiliario castellano, la necesidad de materia prima por los tejedores flamencos y el interés de la Corona en el cobro de determinados impuestos.

Han tenido también importancia las actividades relacionadas con la extracción del hierro en las minas vascas, la textilería en lana, lino, cáñamo y seda, así como la producción naviera en las zonas cantábrica y andaluza, la pesca, la extracción de sal, la confección de prendas de vestir, la fabricación de muebles, los trabajos de orfebrería, tapicería, cerámica, vidriería y azulejos, y las manufacturas de lujo en lo relacionado con pieles, metales y miniaturas.

Respecto al comercio, se manejaron las técnicas empleadas en las zonas europeas de mayor avance en lo mercantil. Gracias a las investigaciones de Hilario Casado se puede hablar del desarrollo gerencial adquirido por los mercaderes castellanos, es decir, el desarrollo de técnicas, instrumentos e instituciones mercantiles aprendidas y tomadas de las zonas flamenca e italiana. Es el dominio del poder del saber. Así, adoptan el sistema toscano de compañías, la contabilidad por partida doble, el seguro marítimo, la letra de cambio y se desarrollaron la banca y los cambistas. Se establecieron colonias de mercaderes y el sistema de ferias de pagos?

En el caso de Burgos, se reconoce su relativa especialización en las relaciones comerciales con el exterior, especialmente en lo concerniente a seguros marítimos, servicios jurídicos tocantes al comercio ${ }^{8}$, además de un temprano desarrollo bancario y que, a partir de 1420, tuvo la concesión de efectuar libremente cambios de oro y plata. Asimismo, es necesario resaltar la activa participación de los

\footnotetext{
${ }^{6}$ TUÑÓN DE LARA, M., Historia de España, T. IV, Feudalismo y consolidación de los pueblos hispánicos (Siglos XI-XV), Barcelona 1983, p. 110.

7 CASADO ALONSO, H.,"El comercio internacional burgalés", en Actas del V Centenario del Consulado de Burgos, Burgos 1994, t. I, p. 187.

${ }^{8}$ GARCÍA SANZ, Á., "Economía y sociedad en la Castilla de los siglos XV y XVI", en Actas del V Centenario del Consulado de Burgos, Burgos 1994, t. I, p. 64.
} 
españoles en bancos y bolsas extranjeras -sobre todo en lo concerniente a seguros y préstamos- en otras ciudades europeas como Brujas y Amberes.

Los mercados y ferias cumplieron un papel destacado y fueron creciendo en número desde la Edad de la Expansión. En el caso de Castilla destacan tres grandes ferias: Medina de Ríoseco, Villalón y Medina del Campo. Esta última, que tenía un papel importante desde inicios del siglo $\mathrm{XV}$, fue considerada como una de las tres mejores del mundo. Allí se realizaron importantes transacciones financieras, además de ser el centro de compra y venta de lana y de artículos suntuarios.

En cuanto al condado de Flandes, su destacado desarrollo urbano desde el siglo VIII estuvo ligado a los grupos religiosos establecidos en Ganda, zona situada en la confluencia de los ríos Escalda y Lys, así como al papel desempeñado en lo político y cultural, por personajes relacionados con el entorno carolingio, dando lugar al nacimiento del condado de Flandes con una serie de elementos favorables para su desarrollo: magnífica ubicación geográfica, buenas conexiones fluviales y marítimas, suelo fértil, abundante ganado lanar, población numerosa y larga tradición en la elaboración de productos textiles en lana y lino, actividad que junto con el comercio recibió la protección de sus gobernantes.

Nuestra atención debe dirigirse especialmente a una ciudad representativa del mundo medieval: Brujas ${ }^{9}$, expresión de la estrecha relación entre desarrollo comercial y renacimiento urbano. Situada en una región pantanosa al fondo del golfo del Zwyn, contaba con la ventaja de su ubicación, próxima al castillo condal y cercana al puente de acceso (Brug). Gracias a los numerosos visitantes se convirtió a fines del siglo X e inicios del XI en un importante centro urbano, con barrios de mercaderes y artesanos, talleres y depósitos, así como la construcción y posterior mejoramiento de sus muelles. Tenía una población estable pero también "flotante", compuesta por mercaderes itinerantes, viajeros, visitantes que se convierten en clientela importante de los productos textiles elaborados por artesanos brujenses.

Los condes fomentaron el desarrollo económico de la región, acrecentando sus territorios y aumentando sus poderes señoriales, siendo las ciudades un apoyo esencial, especialmente en la zona marítima. La actividad textil adquirió más importancia y necesitaron importar lana inglesa en mayores cantidades, especialmente al convertirse en una industria de exportación a mercados importantes, tanto en lo regional como en lo internacional. Las ciudades

\footnotetext{
${ }^{9}$ La bibliografía relacionada con el comercio en Brujas es cada vez más abundante y a ella se han agregado importantes trabajos con nuevos enfoques en lo político y cultural.
} 
flamencas manifestaban su prosperidad por el número de corporaciones textiles y guildas comerciales, protegiendo con salvoconductos a los mercaderes extranjeros, quienes se beneficiaban también de la estabilidad monetaria flamenca y de la existencia del circuito de las ferias de Champaña.

Es importante tener en cuenta la existencia de rutas terrestres, marítimas y fluviales así como el apoyo de la marina flamenca en pleno desarrollo, favoreciendo la presencia de numerosos mercaderes extranjeros. Brujas ha logrado ejercer un control sumamente importante en el comercio internacional de la época, al formar una Hansa con otras 14 ciudades, asociación que se interesaba en el intercambio textil con Inglaterra, mientras que la formada por Gante estuvo ligada al mundo germánico.

Pese a los elementos favorables mencionados, no faltaron dificultades como la falta de continuidad dinástica en el condado que favoreció la intervención francesa. Las complicadas relaciones feudovasalláticas entre los monarcas de Francia e Inglaterra y la difícil situación del conde de Flandes, vasallo del rey de Francia pero dependiente del aprovisionamiento de lana inglesa. Sin embargo, las dificultades internas fueron también importantes como en el caso de Brujas, situada a la entrada del canal del Zwyn, que comenzó a enarenarse desde el siglo XIII, impidiendo el ingreso de barcos de gran calado, debiendo construirse los antepuertos de Damme y Esclusa. Asimismo, reconocemos los comportamientos de las ciudades flamencas y sus grupos dirigentes, inclinados en muchos casos a políticas proteccionistas en lo económico, evitando competencias a sus intereses, especialmente de las manufacturas rurales, cambios en la marina comercial, es el caso de los marinos flamencos -en especial brujenses- quienes se hicieron cada vez más dependientes de la marina inglesa, a la que le encomendaron prácticamente su comercio internacional.

A fines de la Edad Media la Gran Depresión incidió en la prosperidad económica de Flandes, sea por el cambio en las tendencias comerciales que desplazaron a los productos de lujo por otros de menor costo, el desarrollo de la manufactura textil inglesa de menor precio y al alcance de clientes con menores recursos, la pérdida de importancia del circuito de ferias de Champaña y el surgimiento de nuevas ferias más alejadas de Flandes, el desarrollo de ciudades como Amberes con políticas acordes con los intereses de los duques de Borgoña y los grupos mercantiles extranjeros.

Uno de los problemas más importantes es el relacionado con la Guerra de los Cien Años entre Francia e Inglaterra. Flandes debía cumplir con su señor feudal, el rey de Francia; tanto el conde como la nobleza y gran parte del patriciado urbano estaban de acuerdo. Pero, existía un elemento económico 
fundamental, la dependencia flamenca de la lana inglesa. Por tal razón, las corporaciones textiles fueron partidarias de la neutralidad en dicha contienda e inclusive, consideran que era conveniente apoyar las pretensiones inglesas al trono francés.

En lo concerniente a los problemas internos, observamos que algunos son el resultado de situaciones ya existentes, mientras que otros surgen en este período. Un elemento destacado a fines del siglo XIV fue el ascenso de una nueva dinastía gobernante, los duques de Borgoña y las políticas que imponen: centralismo, administración eficaz y restricción de privilegios a centros urbanos insumisos, incluso nuevos intereses en la política internacional, lo que se reflejará en los aspectos militares, diplomáticos e incluso culturales ${ }^{10}$.

Gante y Brujas habían vivido en estrecha dependencia de una economía ligada a los artículos de lujo y trataron de defender sus privilegios. Era difícil adaptarse a los cambios que se presentaban y trataron de enfrentar las dificultades, acentuando el proteccionismo de épocas anteriores, oponiéndose al desarrollo de industrias rurales o cualquier competencia local o extranjera, así como la política centralista borgoñona, incrementaron las luchas urbanas entre los poderosos nobles y patriciado urbano y los grupos menos favorecidos.

Brujas se convirtió en un centro de intercambios internacional donde las representaciones o "colonias" de mercaderes extranjeros eran numerosas y buscaron superar el desabastecimiento de lana inglesa con la española, cambio que no es fácilmente aceptado por las corporaciones textiles ni por los compradores, pues, era de calidad inferior. El golpe de gracia a la difícil situación se relacionó con un problema geográfico: el cierre definitivo del canal del Zwyn en el siglo XV. Los barcos debían desembarcar sus mercancías en las costas del Mar del Norte y transportarlos por vía terrestre hasta Brujas, dando lugar a problemas que afectaban los negocios y la gran mayoría de "Naciones" extranjeras abandonaron la ciudad, a fines del siglo XV o inicios del XVI, de manera temporal o definitiva. Es interesante notar que la Nación española permaneció en Brujas hasta fines del siglo XVI y gracias a esa permanencia sus archivos quedaron en la ciudad y es posible hasta la actualidad consultarlos, a diferencia de aquellos de otras Naciones. (Anexo I).

${ }^{10}$ FLÓREZ, G. C., "Flandes y Borgoña en el contexto inicial de las relaciones internacionales", en Agenda Internacional (Lima), 14 (2000), 


\section{LA CARRERA A FLANDES}

Definimos la Carrera a Flandes como la ruta establecida desde el siglo XIII, entre los puertos cántabros y flamencos para el transporte de diversos productos, principalmente lana, realizado por marinos vascos y vizcaínos. Ese tráfico ayudó a consolidar el poderío marítimo castellano a finales de la Edad Media, gracias a factores internos y externos y a la importante documentación oficial existente, se puede añadir la importante iconografía de las Cantigas a Santa María de Alfonso X el Sabio, mostrando aspectos del comercio lanero e incluso sus dificultades y peligros.

El tráfico marítimo castellano se transformó de una actividad simple y modesta, basada en productos como el hierro, el vino y las diversas variedades de lana en un comercio de amplio alcance basado en el papel de la marina castellana y su flota mercante, la experiencia adquirida en el Atlántico y el Mediterráneo por su personal marinero, favoreciendo la formación de personal marinero y mejoras en técnicas de navegación. Asimismo, la competitividad en lo concerniente a fletes en la zona septentrional, gracias a una política de reducción por parte de los marinos vascos y la conexión entre Burgos y el Cantábrico, especialmente por la relación existente - no siempre fácil por intereses económicos y situaciones políticas entre los ganaderos del Honrado Consejo de la Mesta, los mercaderes de la Universidad de Burgos y los transportistas de las Hermandades.

El tráfico lanar benefició tanto a la ciudad de Burgos como a los mercaderes burgaleses "estantes en Flandes", es decir, residentes, favorecidos por la Universidad de Burgos en 1443. Esta asociación agrupaba a los comerciantes importantes y a los exportadores, en particular los grandes negociantes o traficantes internacionales del comercio marítimo. La preocupación fundamental de la Universidad era la defensa y protección de sus miembros, tanto en el reino de Castilla como en el extranjero. Su interés en favorecer el comercio marítimo servirá de antecedente al Consulado de Burgos, constituido por Real Pragmática del 21 de julio de 1494, y al que se le asigna jurisdicción propia en causas mercantiles. Dicha jurisdicción se extendía a Valladolid, Palencia, Soria y Segovia "el cogollo de las ciudades mercantiles castellanas" y contaba con los puertos de las Cuatro Villas: Castro Urdiales, Santander, San Vicente de la Barquera y Laredo ${ }^{11}$.

\footnotetext{
${ }^{11}$ BASAS FERNÁNDEZ, M., El Consulado de Burgos en el siglo XVI, Madrid 1963, p. 113.
} 
El Consulado de Burgos afirmaba usos y costumbres de la Universidad de Mercaderes de Burgos, es decir, el prestigio y solvencia de una institución dedicada al comercio marítimo, siendo sus objetivos principales:

a) Centralizar el comercio que es considerado de gran interés por los Trastámara y en especial para Isabel La Católica.

b) Organizar el voluminoso tráfico de las flotas del Cantábrico donde se observa desde 1476 a 1499 una clara política de protección a los laneros, transportistas y a la marina.

c) Establecer el monopolio de la exportación lanera (exclusividad de este fletamento por el Consulado), a diferencia de lo que se daba en otras mercancías.

La Carrera de la Lana quedó encomendada a partir de 1494 al Consulado de Burgos y debía organizarse de acuerdo a determinadas normas, muchas de ellas respetando costumbres anteriores. La travesía de los convoyes de barcos que se dirigían desde Bilbao o Laredo y una serie de puertos cantábricos hacia su destino final Flandes, siendo las etapas principales: Burdeos, La Rochela, NantesRuán (Bayona- Dieppe- Harfleur- El Havre) y en ciertos casos puertos ingleses (Bristol-Portsmouth-Southampton)-Brujas (Esclusa-Walcheren- MidelburgoDamme). (Anexo II).

En cuanto al número de barcos podía variar, siete en algunos casos pero en ciertas ocasiones superaban el centenar. Generalmente tenía lugar una vez al año, entre Abril y Mayo, en razón del buen tiempo en la zona para navegar, si bien en ciertas ocasiones pudieron realzarse dos veces al año.

La preparación de la Carrera era sumamente extensa y compleja, teniendo como pasos previos al fletamento: el contrato de las lanas, la esquila, el recibo y lavado, el estibado, listado y margado de las sacas. Todo lo mencionado era responsabilidad de la Universidad de Burgos, siendo sus cónsules y priores los encargados de la reglamentación y vigilancia, confirmando así la tradición mercantil burgalesa, e indicando igualmente cierta política de control monárquico que desde 1491 se manifestaba en asuntos tales como control de entrada y salida de productos mediante registros.

Colocadas las sacas de lana en los barcos, comenzaba la difícil etapa del transporte a Flandes, complicada en muchos casos por la organización de la flota principalmente por razones políticas y económicas, si bien podían participar otros factores como las rivalidades de puertos o ciudades, o de transportistas y mercaderes. Un aspecto fundamental era la defensa de dichas flotas y los mercaderes debían hacerse cargo de esos gastos, mediante el pago 
del impuesto de avería, amén de otros como mantenimiento de puentes y caminos, despachos de correos y mensajeros. Esa defensa y armamento de los navíos de la Carrera era primordial puesto que piratas y corsarios, así como flotas extranjeras -inglesas, francesas o hanseáticas-, creaban inseguridad constante en esa ruta.

\section{PELIGROS Y SALVAGUARDAS DE LOS MERCADERES CASTELLANOS EN LA CARRERA A FLANDES}

El transporte era un factor de gran importancia en el comercio porque afectaba el precio de los productos y podía variar de acuerdo a las estaciones, los productos y las rutas empleados, incluso por coyunturas políticas o sociales. En el caso de la zona y período estudiados, los comerciantes optaron por la ruta marítima que permitía mayor rapidez y menores costos en el transporte. Teniendo en cuenta las diferencias existentes entre las tradiciones de navegación septentrional y mediterránea, John Parry ${ }^{12}$ ha señalado que la primera se basaba en la práctica más que en la teoría, permitiendo a los marineros atlánticos lograr superioridad en aspectos tales como el conocimiento de mareas, corrientes, costas y obstáculos, así como el manejo de la sondaleza y la conducción en alta mar.

Además, se debe tener en cuenta las embarcaciones usadas, en el caso de Castilla, mantuvo una gran variedad de ellas como lo reconoce la Cofradía de Bermeo cuando habla de carabelas, barcos, pinazas, navíos, galeras o cocas ${ }^{13}$, si bien nuestra documentación menciona otras denominaciones. Generalmente, provienen Bilbao y Portugalete pero también de Andalucía y su tonelaje varía entre 100 a 1000 toneladas, provistos con velas o remos, timón de codaste, medios para medir latitud y distancia, así como cañones para su defensa. A fines de la Edad Media se realizaron importantes avances tales como rapidez en las travesías y menor costo en el transporte, debido principalmente a la mayor capacidad de los barcos, sin embargo otras no lograron superarse.

Los polos de atracción económica eran fundamentalmente dos: Italia (Génova, Venecia, Florencia) y Flandes (Brujas), Ellos correspondían a las dos corrientes preferenciales de la época: la mediterránea que conectaba el mundo ibérico a través de las costas aragonesa y andaluza con el comercio de Levante y la europea continental y nórdica que unían el Mar del Norte y las costas del Atlántico con el Báltico y a la que Castilla se integraba por el mar Cantábrico.

\footnotetext{
${ }^{12}$ El descubrimiento del Mar, Barcelona 1989.

${ }^{13}$ GUIARD, T., La industria naval vizcaina (Anotaciones jurídicas y estadísticas desde sus origenes hasta 1917), Bilbao 1968, pp. 46-47.
} 
Esos puertos castellanos mantenían una estrecha relación con aquellos de Vizcaya, Galicia y País Vasco, destacando por un tráfico muy activo San Sebastián, Bilbao y La Coruña, así como otros conocidos por su industria naval y comercio: Fuenterrabía, Avilés, Ondarroa, Pontevedra, Guetaria y Bayona.

Respecto a la jerarquía de productos comercializados en este período, podemos clasificarlos en productos de exportación, castellanos y de otras regiones españolas, inclusive mediterráneos; los de importación destinados a Castilla principalmente y aquellos en tránsito, transportados por los marinos vascos entre puertos del Atlántico y del Mar del Norte, correspondientes a Francia, Inglaterra y Flandes. Teniendo en cuenta la documentación y bibliografía consultadas hemos elaborado el cuadro adjunto. (Anexo III).

No obstante, consideramos que los testimonios de época provenientes de residentes o viajeros, proporcionan una imagen muy real de ese comercio. Así, a fines del siglo XIII, un brujense señalaba entre los múltiples productos que se comercializaban en tierras flamencas:

“...del reino de Castilla vienen granos de escarlata, cera, cordobanes, badanas, hilazas, lana, pieles, mercurio, sebo, comino, anís, almendras y fierro, Del reino de León vienen otras cosas como hemos mencionado antes pero sin el fierro... Del reino de Galicia viene manteca, mercurio, vino, cueros, pieles y lana"14.

Dos siglos más tarde, Pero Tafur, importante viajero español ${ }^{15}$, se interesaba tanto por los habitantes de la ciudad y sus actividades, así como por las mercaderías que se ofrecen: telas, paños, frutas de Castilla, vinos de Grecia, brocados e incluso mencionaba la importancia de los mercaderes burgaleses.

Las dificultades que se presentaron en la Carrera a Flandes las clasificamos en:

a) Naturales como las tempestades, la carencia de visibilidad, las neblinas entre otros peros "Pero, para la mayoría, [el mar] ha quedado durante mucho tiempo como disuasión y es por excelencia el lugar del miedo" $"$.

b) Técnicas relacionadas con la capacidad limitada de los barcos y sus instrumentos, las dificultades en el acceso a los puertos y especialmente técnicas comerciales.

${ }^{14}$ PAVIOT, J., Bruges 1300-1500, Paris 2002, p.8

${ }^{15}$ TAFUR, P., Andanzas y viajes de un hidalgo español, Madrid 1995, pp. 134- 135.

${ }^{16}$ DELUMEAU, J., El miedo en Occidente (siglos XIV-XVIII) Una ciudad sitiada, Madrid 2012, p. 49. 
c) Humanas referidas a los miembros de la tripulación, su número, preparación y trabajos que realizaban, problemas con las autoridades por abusos, maltratos, multas e instancias de justicia y muy especialmente los ataques de piratas y corsarios ${ }^{17}$. Sin embargo, debemos tener en cuenta problemas nacionales o internacionales ${ }^{18}$ y que afectaban la seguridad en las rutas, especialmente marítimas, con los consiguientes ataques, bloqueos, asedios, naufragios provocados en zonas costeras entre otros. Existía además un elemento primordial en las relaciones internacionales de la época: la reciprocidad, que permitía la ejecución de medidas de represalia, las que eran una amenaza constante para los comerciantes. De allí la preocupación por realizar acuerdos con la autoridades de las zonas en donde tales actividades estaban muy desarrolladas. Naturalmente, no siempre tuvieron éxito, inclusive monarquías como la inglesa en la época de los Lancaster se veía imposibilitada de controlar la situación.

Nuestra documentación refleja el temor de los mercaderes de la época por los problemas mencionados, al igual que otras situaciones que podían darse. Es el caso de embargos, remates, confiscación de bienes, detención y toma de naves, deudas impagas, prisión por falsas acusaciones, abusos y maltratos por parte de las autoridades, falta de apoyo por la justicia lugareña, asesinatos, multas injustas, pleitos y rivalidades con otros mercaderes.

Asimismo, las dificultades creadas por las restricciones o vedas en las importaciones y/o exportaciones, es el caso de los caballos, metales o lana; los impuestos o derechos especiales (el de la etapa, el del lastre, el diezmo de la piratería). Ciertos monopolios y la pérdida de los privilegios podían solucionarse mediante arbitrajes, acuerdos privados, intervención de jueces y comisarios, regulaciones de tribunales y consulados, participación de monarcas con cartas requisitorias, procesos perfeccionados con la participación de testigos, documentación notarial autenticada, intervención de autoridades y castigos, así como reglamentaciones sobre mercancías.

Los mercaderes se veían afectados por múltiples problemas, relacionados con sus actividades comerciales o por sus relaciones con otros negociantes y, en especial, con las autoridades. De allí la importancia, inicialmente, de buscar soluciones muy simples y luego más complejas para su protección. Esas medidas pueden considerarse desde dos perspectivas: aquellas que

\footnotetext{
${ }^{17}$ Eran numerosos en Galicia, Vizcaya, Bretaña, Zelanda y Plymouth

${ }^{18}$ Es el caso de la guerra de los Cien Años, las guerras civiles en Castilla y los conflictos en Flandes, Bretaña y Borgoña.
} 
surgían por iniciativa de los interesados (mercaderes y armadores), y las relacionadas con las autoridades en cierta manera vinculadas a las anteriores.

Entre las primeras destacan las Hermandades que eran asociaciones que fomentaban la solidaridad entre sus miembros, así como su participación en intervención en la vida pública. Una de las más representativas es la Hermandad de la Marina de Castilla con Vitoria, que tuvo notable poderío nacional e internacional gracias al control ejercido en la "marca marítima castellana" durante la coyuntura creada en el siglo XIV por la guerra de los Cien Años y los problemas en Flandes. Entre las asociaciones de mercaderes destacó la mencionada Universidad de los Mercaderes de Burgos por su intervención en el tráfico lanar, desde las mesetas castellanas hasta la ciudad de Brujas.

En lo que respecta a las medidas de protección concedidas por las autoridades, buscaron, a pesar de las diferencias geográficas y temporales, orden, paz y seguridad, así como el cumplimiento de compromisos contraídos y la reciprocidad en las medidas tomadas. Esas disposiciones fueron muy variadaslegislativas, políticas, jurídicas y económicas, abarcando tanto a personas como a los transportes. Destacan la firma de acuerdos y en especial, se adquirieron a precios muy elevados, documentos tales como salvoconductos y salvaguardas, cartas de marca y represalia. Lamentablemente, no fueron todo lo útiles que se esperaban ya que no eran respetados en época de guerra, ni siquiera durante los períodos de paz o treguas entre los combatientes.

En general, los mercaderes debían protegerse de daños o pérdidas a sus mercancías e incluso sus personas, puesto que asaltos, robos, saqueos, capturas y secuestros no eran raros en la época, especialmente en zonas costeras bretonas o, irlandesas. Lo anterior, explica la importancia de utilizar medios más efectivos, defensa y armamento de sus naves y convoyes.

Hemos estudiado a una quincena de mercaderes castellanos, estantes en Flandes a fines del siglo $\mathrm{XV}$, algunos de ellos mencionados en diferentes años como Juan de Arbolancha, Fernando de Salinas, Fernando del Hoyo, Rodrigo Catalán. Ellos manifiestan su confianza en la justicia del monarca, si bien en ciertos casos sienten recelo por la actuación de los funcionarios. Consideran que la honestidad en sus transacciones y cumplimiento de sus obligaciones deben estar presentes en su vida profesional evitarían daños futuros, como pueden ser las sanciones económicas u otras medidas punitivas.

Son numerosas las acusaciones relacionadas con el uso de la fuerza y violencia en asaltos, robos, secuestros de mercancías, realizados incluso por otros mercaderes de forma regular y constante. Algunas no tienen motivo 
aparente, si bien otras eran resultado de la reciprocidad aplicada en muchos casos en respuesta a los daños o medidas sufridos previamente.

Los conflictos nacionales e internacionales no favorecían la solución rápida de los problemas y esa lentitud complicaba cada vez más los trámites. Es interesante señalar que la documentación indica generalmente las situaciones que podían derivar en caso de incumplimiento de las disposiciones. Queda la interrogante acerca de la efectividad que tuvieron esas disposiciones para los afectados. 


\section{Anexo I}

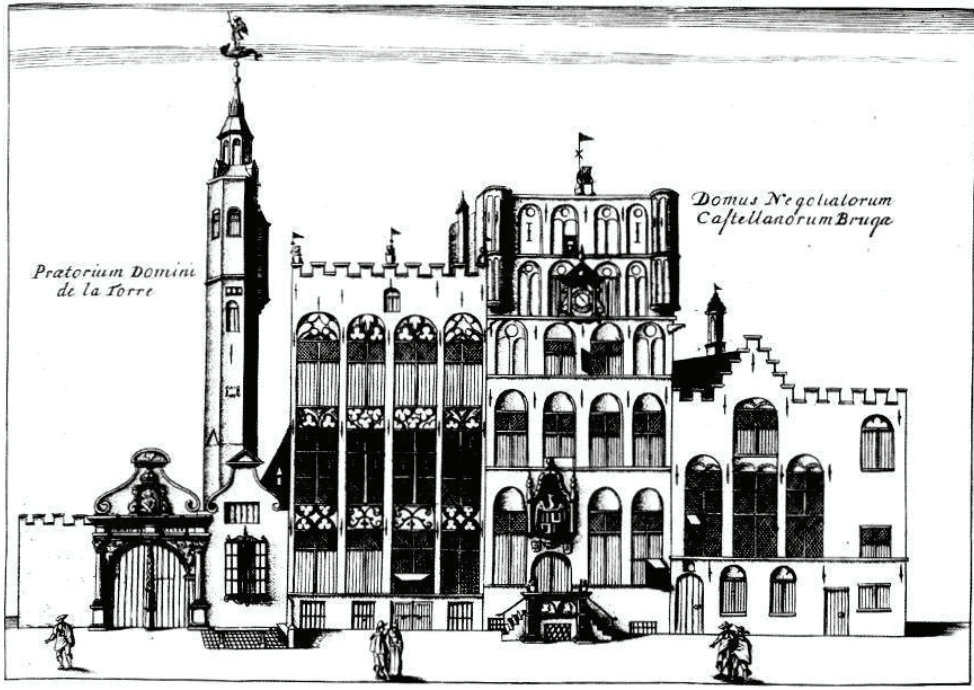

Grabado de la Casa de los Mercaderes de la Nación de Castilla en Brujas Antoine Sanderus, S.XVI. Bolsa de Comercio (Madrid-España)

\section{Anexo II}

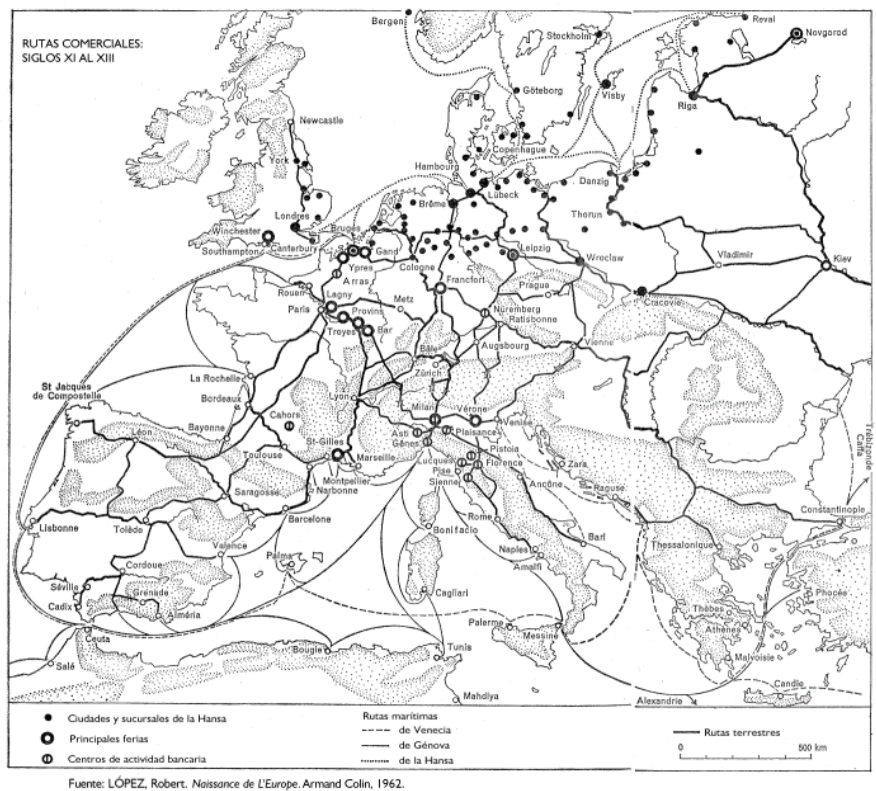

Tomado de LÓPEZ, Robert. Naissance de L'Europe, Paris 1962, Armand Colin Ed. 


\section{Anexo III}

\section{Cuadro de productos comercializados}

\begin{tabular}{|c|c|c|}
\hline PRODUCTOS DE EXPORTACIÓN & PRODUCTOS DEIMPORTACIÓN & PRODUCTOS EN TRÁNSITO \\
\hline 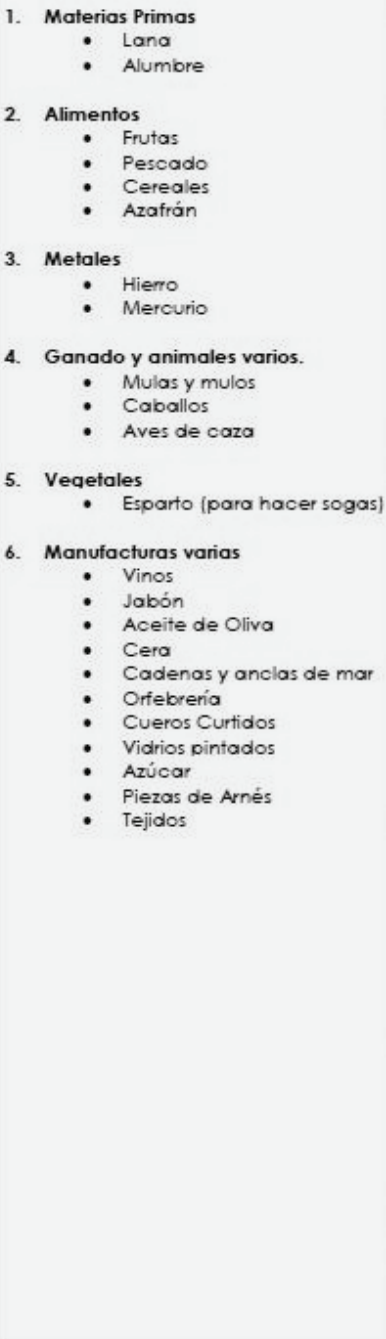 & 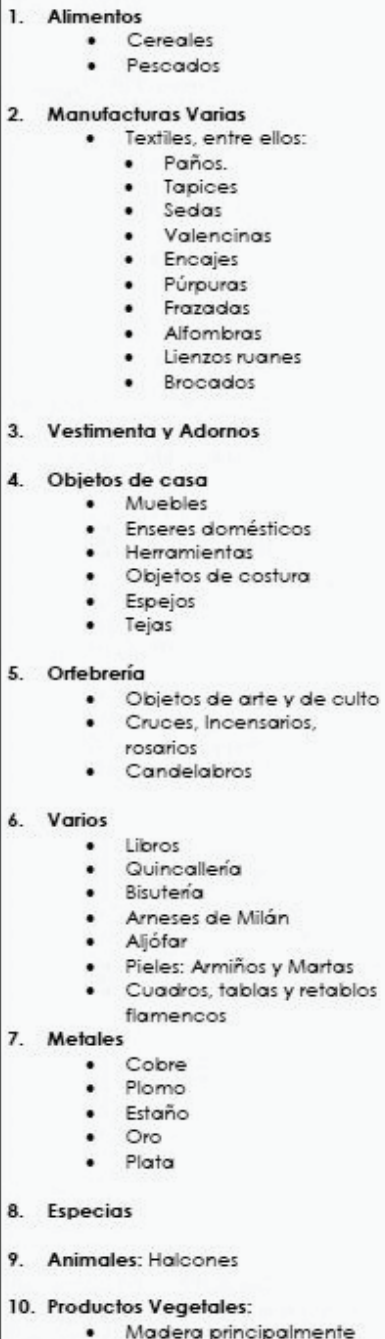 & $\begin{array}{l}\text { - Vinos franceses sobre todo } \\
\text { de Burdeos a Inglaterra. } \\
\text { Escocia, Flandes y } \\
\text { Alemania } \\
\text { - Pastel de Tolosa o 'glasto' } \\
\text { (tinte azul para los textiles } \\
\text { flamencos) } \\
\text { - Madera } \\
\text { - Carbón de piedra inglés } \\
\text { - Pescado (arenques en } \\
\text { - Especial) } \\
\text { - Cerámica }\end{array}$ \\
\hline
\end{tabular}

Fuente: G.C. Flórez. 